\title{
Analysis of Dose by Items According to Act on Safety Control of Radiation Around Living Environment
}

\author{
Cheonsoo Jeong, ${ }^{* * *}$, Hyunji $\mathrm{Oh}^{*}$, Jieun Lee*, Sumin Jo*, Sohyun Park ${ }^{*}$ \\ Department of Radiological Science, Mokpo science University* \\ Department of Radiation Science \& Technology, Chonbuk University ${ }^{* *}$
}

\section{생활주변방사선안전관리법 시행에 따른 항목별 선량 분석 \\ 정천수 ${ }^{* * *}$, 오현지*, 이지은*, 조수민 ${ }^{*}$ 박소현* \\ 목포과학대학교 방사선과*, 전북대학교 방사선과학기술학과**}

\begin{abstract}
The study attempted to analyze items presented in Act on safety control of radioactive rays around living environment, which has been recently enacted. The test items have been divided into cosmic rays, cosmic rays, terrestrial radiation, and byproduct, etc., and the selected locations for measurement included an airplane at $8000 \mathrm{~m}$ in the air, mountainous area at $1000 \mathrm{~m}$ above sea level, $15 \mathrm{~m}$-underground building, construction site, and seashore at $0 \mathrm{~m}$ altitude.

The test showed that, based on cosmic rays, plane at $8000 \mathrm{~m}$ in the air had $4.91 \mathrm{mSv} / \mathrm{y}$ of effective dose per year. The mountainous area at $1000 \mathrm{~m}$ above sea level, which was chosen to measure cosmic rays and terrestrial radiation, was measured $0.35 \mathrm{mSv}$ higher than the seashore at $0 \mathrm{~m}$ in altitude due to the effect of cosmic rays and terrestrial radiation from the greater height above sea level. The construction site, chosen as a location to measure byproduct, showed the highest value among the items with $6.66 \mathrm{mSv}$, which is as 10times high as that of a completed building. The seashore at $0 \mathrm{~m}$ in altitude had $5.96 \mathrm{mSv}$, and, $15 \mathrm{~m}$-underground building, based on terrestrial radiation, was the lowest with $4.91 \mathrm{mSv}$. This suggests that, despite the assumption that terrestrial radiation will have greater effect deeper underground, it did not affect inside the building significantly.

This study showed that the items presented in Act on safety control of radioactive rays around living environment were not close to effective dose limit for radiation workers proposed by ICRP. However, they were between 4 and 7 times higher than that for general public. This suggests that there should be continuous research on and attention to Safe Management of Daily Surrounding Radiation Act, which is still at its beginning stage.
\end{abstract}

Key Words: Act on safety control of radioactive rays around living environment. cosmic rays, terrestrial radiation, byproduct 
선, 공정부산물 등으로 나누고, 그에 따른 측정 장소를 상공 $8000 \mathrm{~m}$ 의 비행기, 해발 $1000 \mathrm{~m}$ 의 산악지대, 지하 $15 \mathrm{~m}$ 건 물, 건설 현장, 해발 $0 \mathrm{~m}$ 의 바닷가를 선정하였다.

실험결과 우주방사선을 기준으로 상공 $8000 \mathrm{~m}$ 비행기에서는 유효선량이 연간 $2.45 \mathrm{mSv}$ 로 측정되었다. 우주방사선 과 지각방사선의 측정 장소로 선정된 해발 $1000 \mathrm{~m}$ 산악지대는 기준점인 $0 \mathrm{~m}$ 인 바닷가에 비해 $0.17 \mathrm{mSv}$ 높게 측정되었 다. 공정부산물의 측정 장소로 선정된 건설 현장은 $3.32 \mathrm{mSv}$ 로 실험항목 중 가장 높은 수치를 나타내었다. 이는 완공 된 건물 보다 약 5 배 정도 높은 선량이라는 것을 알 수 있었다. 해발 $0 \mathrm{~m}$ 인 바닷가는 $2.89 \mathrm{mSv}$ 로 측정되었고, 지각 방 사선을 기준으로 설정된 지하 $15 \mathrm{~m}$ 건물에서는 $2.36 \mathrm{mSv}$ 로 가장 낮게 측정되었다. 이를 통해, 지하로 내려갈수록 지각 방사선을 많이 받을 것으로 예상되었으나 건물 안에서의 지각 방사선은 크게 영향을 주지 않는 것을 알 수 있었다.

본 연구를 통해 생활주변방사선안전관리법에서 제시된 각 항목들은 ICRP에서 제시한 방사선작업종사자의 연간 유 효선량 기준에는 크게 미치지 않았다. 하지만 일반인의 연간 유효선량보다는 약 2 배 정도 높은 선량인 것을 알 수 있었다. 이를 통해 아직 시행 초기 단계인 생활주변방사선안전관리법에 대한 지속적인 연구와 관심이 필요한 것으로 사료된다.

중심단어: 생활주변방사선안전관리법, 우주방사선, 지각방사선, 공정부산물

\section{I. 서 론}

생활주변방사선안전관리법이란 원료물질 및 공정부 산물 및 가공제품에 함유된 천연방사성 핵종에서 방 출되는 방사선(단, 「원자력 안전법」에 따라 관리 되 는 핵물질에서 방출되는 방사선은 제외), 우주방사선, 지각방사선, 재활용고철에 포함된 방사성 물질에서 방 출되는 방사선으로 정의 된다. 국가는 생활주변방사선 으로부터 국민의 건강과 환경을 보호하기 위하여 생 활주변방사선의 안전관리에 필요한 시책 마련을 해야 하고 생활주변에서 접할 수 있는 방사선의 안전관리 에 관한 사항을 규정함으로써 삶의 질을 향상 시키고 공공의 안전에 이바지하기 위해 「생활주변방사선안 전관리법」를 시행하였다 ${ }^{[1]}$.

최근 후쿠시마 원자력발전소 사고 이후 원자력 관 련 작업종사자 이외에도 일반인들의 관심이 높아지고 있는 가운데 생활 속에서 흔히 볼 수 있는 콘크리트, 타일, 석고보드, 벽지 등에서 방사성핵종이 검출되었 다는 보고 등은 방사선 피폭에 대한 일반인의 염려를 크게 증대시켰다 ${ }^{[2]}$. 보고에 따르면 건축자재 중 콘크 리트는 건축물의 대부분을 차지하고 있고 천연방사성 물질에 기인한다. 콘크리트의 경우 그 구성은 골재, 시 멘트, 물, 공기 등으로 이루어져 있으며, 자재의 성능 향상을 위하여 플라이애시, 고로슬래그, 실리카품 등 의 산업 부산물을 혼화재로 사용하기도 한다. 상기 콘 크리트의 구성성분으로 사용되고 있는 물질들은 천연
방사성핵종을 함유하고 있는데, 이러한 천연방사성핵 종 중 외부피폭을 유발하는 감마 방출 선원은 우라늄 계열 핵종 중 외부피폭을 유발하는 감마 방출 선원은 우라늄 계열 핵종, 토륨 계열 핵종, ${ }^{40} \mathrm{~K}$ 를 포함한다 $[3],[4]$

주거 공간 공기 중의 라돈에 의한 피폭과 고공비행 으로 인한 우주선 피폭이 있다 ${ }^{[5]}$. 이를 전후하여 우주 선 선량계측에 대한 연구가 활발히 진행되었으며, 항 공승무원에 대한 피폭관리 대책들이 마련되었다 ${ }^{[6],[7]}$. 1996년 5월에 발표된 유럽연합 기본안전지침에서는 연간 $1 \mathrm{mSv}$ 를 초과하여 피폭 될 것으로 예상되는 항공 승무원에 대하여 적절한 피폭선량 평가가 이루어져야 하며, 더 나아가 일정 수준 이상에 피폭된 항공승무원 에 대하여 추가 피폭을 줄이기 위한 목적으로 비행스 케줄을 조정 할 것을 규정하고 있다 ${ }^{[8]}$. 또한 일부 인구 밀집지역의 지하수에서 방사성물질이 검출되었고, 음 식물 중의 ${ }^{40} \mathrm{~K}$ 와 우라늄, 토륨 등의 붕괴에 의해 생성 된 ${ }^{222} \mathrm{Rn}$ 가스가 지하시설에서 자연방사선의 허용치를 초과하여 검출된 것으로 보고되었다 ${ }^{[9],[10]}$. 국립공원이 나 해발고도가 높은 산악지대에는 실시간 모니터링이 어렵고 측정 자료도 부족하다[11]. 지금까지 보고된 자 연방사선에 대한 연구에서는 암반으로 구성된 곳에서 지각에 의한 환경방사선이 증가하는 것으로 알려져 있으며, 해발고도가 높을수록 우주선의 영향으로 평지 에 비해 방사선수치가 높게 측정된 것으로 보고되었 다 ${ }^{[12]}$. 환경방사선은 지리적 요인, 암석과 토양의 구성 
및 해발고도의 높이에 따라 차이를 보이는 것으로 알 려졌다 ${ }^{[11]}$.

본 연구의 목적은 2012년 7월 26일에 생활주변방사 선안전관리법에 시행에 따른 항목을 정하고 그에 따 른 선량을 측정하는 것이다. 연구 결과는 항목별 측정 된 결과 값을 국제방사선방호위원회(이하 ICRP)에서 권고한 작업종사자 $20 \mathrm{mSv} / \mathrm{y}$, 일반인 $1 \mathrm{mSv} / \mathrm{y}$ 값과 비 교 분석하여 생활주변방사선안전관리법에 대한 이해 를 높이고자 한다.

\section{II. 재료 및 방법}

\section{1. 실험기기}

알파, 베타, 감마 및 $\mathrm{X}$ 선의 낮은 수준을 $\mathrm{mR} / \mathrm{hr}$ 과 $\mathrm{CPM}$ 그리고 Total/time을 측정하는 $\mathrm{RADIATION}^{\circledR}$ 의 inspector+를 사용하였다. 각 단위의 검출되는 범위는 $\mathrm{mR} / \mathrm{hr}$ 는 0.01 1000, CPM은 0 350000, Total/time은 1 9999000 까지 측정 가능하고 표면의 오염과 방사성 핵종에서 작업하는 동안 방사선 노출을 모니터링하고 환경오염과 불활성 기체, 낮은 에너지 방사성 핵종을 검출한다.

\section{2. 실험 방법}

생활주변방사선안전관리법에서 제시한 항목을 우주 방사선, 지각방사선, 공정부산물 등으로 나누고, 측정 장소는 상공 $8000 \mathrm{~m}$ 의 광주 제주행 비행기(왕복 1시간) 와 해발 $1000 \mathrm{~m}$ 의 지리산 노고단, 지상 30 층의 광주 $\mathrm{K}$ 빌딩 지하 $15 \mathrm{~m}$ 건물 안, 무안군 남악면의 한 아파트 공사장 7 층, 신안군 압해면 해발 $0 \mathrm{~m}$ 의 바닷가를 대상 으로 선정하였다. 측정 기구인 inspector+를 사용하여 2013년 5월 1일부터 7월 9일까지 3개월 동안 각 장소 에서 1 시간 동안 10 분씩 총 6 회 동안 $\mathrm{mR} / \mathrm{hr}$ 와 $\mathrm{CPM}$ 단 위로 측정하였다. 조사선량 단위인 $\mathrm{mR} / \mathrm{hr}$ 로 측정한 결과 값을 유효선량 단위인 $\mathrm{mSv} / \mathrm{y}$ 으로 다음과 같이 환산하여 표기하였다.

$$
\begin{aligned}
& 1 \mathrm{R}=0.877 \mathrm{rad} \text { at air, } 1 \mathrm{R}=0.977 \mathrm{rad} \text { at bone, } \\
& 1 \mathrm{R}=1 \mathrm{rad} \text { at human, } 1 \mathrm{~Gy}=1 \mathrm{~J} / \mathrm{kg}=100 \mathrm{rad}, \\
& 1 \mathrm{~Sv}=100 \mathrm{rad}
\end{aligned}
$$

\section{III. 연구 결과}

\section{1. 시간당 측정된 선량}

해발 $0 \mathrm{~m}$ 인 바닷가 기준으로부터 상공 $8000 \mathrm{~m}$ 의 비 행기 안과 해발 $1000 \mathrm{~m}$ 산악지대, 지하 $15 \mathrm{~m}$ 건물과 건 설현장을 기준으로 측정 하였다. 10 회 동안 측정한 결 과 가장 높은 선량은 해발 $1000 \mathrm{~m}$ 산악지대에서 $0.050 \mathrm{mR} / \mathrm{hr}$ 이며, 가장 낮은 선량은 상공 $8000 \mathrm{~m}$ 비행 기에서 $0.016 \mathrm{mR} / \mathrm{hr}$ 로 측정되었다. 평균 선량은 건설현 장에서 $0.076 \mathrm{mR} / \mathrm{hr}$ 로 가장 높게 측정되었다. 바닷가와 산악지대에서는 $1000 \mathrm{~m}$ 차이에도 불구하고 평균 선량이 $0.004 \mathrm{mR} / \mathrm{hr}$ 로 미미한 차이를 보였고 비행기와 지하 $15 \mathrm{~m}$ 건물은 최고치에서는 $0.012 \mathrm{mR} / \mathrm{hr}$, 최저치에서는 $0.009 \mathrm{mR} / \mathrm{hr}$ 의 차이가 있지만 평균 선량은 같은 것으로 확인되었다[Table 1].

\section{1 분 동안 검출된 방사선의 수}

$\mathrm{CPM}$ 이란 Count Per Minute의 약자로 분 당 측정되 는 방사선 신호의 개수의 단위이다. 측정결과 건설현 장에서 $73 \mathrm{CPM}$ 으로 가장 높게 측정되었으며, $8000 \mathrm{~m}$ 상 공 비행기에서 $34 \mathrm{CPM}$ 으로 가장 낮게 측정되었다. 비 행기와 지하 건물은 시간당 평균 선량은 $0.056 \pm$ $0.001 \mathrm{mR} / \mathrm{h}$ 로 같은 값으로 측정되었으나, 방사선 신호 의 개수는 $10 \mathrm{CPM}$ 차이로 다르게 측정되는 것을 알 수 있었다[Table 2].

Table 1. The measured dose per hour

\begin{tabular}{cccc}
\hline & $\operatorname{Max}$ & $\min$ & Avg \\
\hline 상공 $8000 \mathrm{~m}$ 비행기 & 0.044 & 0.016 & $0.028 \pm 0.01$ \\
\hline 해발 $1000 \mathrm{~m}$ 산악지대 & 0.050 & 0.025 & $0.035 \pm 0.00$ \\
\hline 지하 $15 \mathrm{~m}$ 건물 & 0.032 & 0.025 & $0.027 \pm 0.001$ \\
\hline 해발 0m 바닷가 & 0.043 & 0.028 & $0.033 \pm 0.004$ \\
\hline 건설현장 & 0.043 & 0.034 & $0.038 \pm 0.003$ \\
\hline & & unit $: \mathrm{mR} / \mathrm{hr}$
\end{tabular}

Table 2. Dose of detected radiation 1 minute

\begin{tabular}{cc}
\hline & count \\
\hline 상공 $8000 \mathrm{~m}$ 비행기 & 34 \\
\hline 해발 $1000 \mathrm{~m}$ 산악지대 & 71 \\
\hline 지하 $15 \mathrm{~m}$ 건물 & 44 \\
\hline 해발 $0 \mathrm{~m}$ 바닷가 & 67 \\
\hline 건설현장 & 73 \\
\hline & unit : $\mathrm{cpm}$
\end{tabular}




\section{3. 생활주변방사선과 유효선량}

각 항목별로 측정된 선량을 ICRP에서 제시한 방사 선작업종사자와 일반인의 유효선량과 비교하기 위해 연간 평균선량으로 환산하였다. 환산된 선량은 방사선 작업종사자의 유효선량인 $20 \mathrm{mSv}$ 와는 큰 차이를 보이 며 낮게 측정되었다. 하지만 일반인의 유효선량인 $1 \mathrm{mSv}$ 와 자연방사선량인 $2.4 \mathrm{mSv}$ 보다는 높게 측정된 것 을 알 수 있었다. 측정된 생활주변방사선량은 평균 $5.75 \mathrm{mSv}$ 로 일반인의 $1 \mathrm{mSv}$ 보다 약 5 배 넘는 수치를 나 타내었다.

Table 3. The effective dose equivalent

\begin{tabular}{cc}
\hline & Avg \\
\hline 상공 $8000 \mathrm{~m}$ 비행기 & 0.00028 \\
\hline 해발 $1000 \mathrm{~m}$ 산악지대 & 0.00035 \\
\hline 지하 $15 \mathrm{~m}$ 건물 & 0.00027 \\
\hline 해발 $0 \mathrm{~m}$ 바닷가 & 0.00033 \\
\hline 건설현장 & 0.00038 \\
\hline &
\end{tabular}

\section{$\mathrm{I}$. 고찰 및 결론}

2012년 7월 26일에 시행된 「생활주변 방사선 안전 관리법 시행령」 제 10 조 (승무원에 대한 안전조치 등)와 「생활주변 방사선 안전 관리법」제 18조 (우주방사선의 안전관리 등)에 제시된 항목들을 분석하고자 하였다. 생활주변방사선안전관리법에서 제시한 항목을 우주방 사선, 지각방사선, 공정부산물 등으로 나누고, 그에 따 른 측정 장소를 우주방사선은 상공 $8000 \mathrm{~m}$ 의 비행기, 우주방사선과 지각방사선은 해발 $1000 \mathrm{~m}$ 의 산악지대, 지각방사선은 지하 $15 \mathrm{~m}$ 건물, 공정부산물은 건설 현 장, 그리고 모든 기준이 되는 곳은 자연방사선으로 영 향을 가장 적게 받는 곳으로 예상되는 해발 $0 \mathrm{~m}$ 의 바 닷가를 대상으로 선정하였다. 각 항목들을 $\mathrm{mR} / \mathrm{h}$ 로 측 정한 결과 값을 $\mathrm{mR}$ 을 $\mathrm{mSv}$ 로 환산하고 시간(h)을 하루 24 시간 365 일로 계산하여 분석한 결과는 다음과 같다.

첫째, 우주방사선을 기준으로 상공 $8000 \mathrm{~m}$ 비행기에 서는 유효선량이 연간 $2.45 \mathrm{mSv}$ 로 측정되었다. 이는 ICRP 권고안에 방사선작업종사자 연간 유효선량 기준 인 $20 \mathrm{mSv}$ 를 넘지 않았다. 하지만 일반인의 유효선량
기준인 $1 \mathrm{mSv}$ 를 $1.45 \mathrm{mSv}$ 나 초과하였고 다른 문헌에서 는 항공 승무원은 연간 $2.62 \mathrm{mSv}$ 내외로 피폭되는 것으 로 알 수 있었다. 우주방사선의 영향을 직접 받는 상 공 $8000 \mathrm{~m}$ 비행기에서 가장 높게 측정 될 것 같았지만 알루미늄 합금과 유리 질 섬유 등과 같은 재질로 이루 어진 비행기 동체에서 많은 차폐가 되어 오히려 가장 낮게 측정 되었다. 방사선작업종사자의 연간 유효선량 보다는 낮지만 일반인의 유효선량보다 약 1.5 배 정도 의 높은 선량을 나타냈기 때문에 비행기 안의 승무원 과 승객들에 대한 방사선 피폭은 지속적인 관심과 연 구가 필요할 것으로 사료된다 ${ }^{[13]}$.

둘째, 지각방사선의 영향을 받는 지하 $15 \mathrm{~m}$ 건물의 실험결과 $2.36 \mathrm{mSv}$ 로 실험 항목 중 가장 낮은 수치로 측정되었다. 지하로 내려갈수록 지각 방사선을 많이 받을 것으로 예상 하였으나 건물 안에서는 지각 방사 선은 크게 영향을 주지 않는 것을 알 수 있었다. 그리 고 우주방사선과 지각방사선의 영향을 받는 해발 $1000 \mathrm{~m}$ 산악 지대는 높은 해발 고도로 인한 우주 방사 선과 암석으로 이루어져 있어 $3.06 \mathrm{mSv}$ 라는 수치가 측 정되었고 이 수치는 ICRP에서 권고한 자연 방사선량 인 $2.4 \mathrm{mSv}$ 보다 높은 수치로서 등산을 자주하는 등산 객들도 조금 주의를 기우릴 필요가 있다고 사료된다.

셋째, 공정부산물의 측정 장소로 선정된 건설 현장 의 실험결과 $3.32 \mathrm{mSv}$ 로 실험항목 중 가장 높은 수치를 나타내었다. 건설 현장의 경우 콘크리트에서 다량의 방사선이 나오는 것으로 알려져 있다. 콘크리트 내 우 라늄계열, 토륨계열, $40 \mathrm{~K}$ 핵종의 농도에 따라 공기 중 흡수 선량률은 $0.80,097,0.08 \mathrm{nGy}$ h-1/Bq kg-1 이었으 며, 유효 선량률은 $0.57,0.69,0.058 \mathrm{nSv}$ h-1/Bq kg-1 이 고 완공된 건물의 연간 유효선량은 $0.59 \mathrm{mSv}$ 로 평가 되 었다 ${ }^{[2]}$. 이는 건설 현장의 $3.32 \mathrm{mSv}$ 의 측정값과 비교했 을 때 완공된 건물 보다 약 3 배 정도 높은 선량이라는 것을 알 수 있었다.

본 연구를 통해 생활주변방사선안전관리법에서 제 시된 우주방사선, 지각방사선, 공정부산물 등은 ICRP 에서 제시한 방사선작업종사자의 연간 유효선량은 연 간 $20 \mathrm{mSv}$ 인데 이 기준에는 크게 미치지 않았다. 하지 만 일반인의 연간 유효선량은 연간 $1 \mathrm{mSv}$ 인데 이 수치 보다는 약 2 3배 정도 높은 선량인 것을 알 수 있었 다. 이를 통해 아직 시행 초기 단계인 생활주변방사선 
안전관리법에 대한 지속적인 연구와 관심이 필요한 것으로 사료된다.

\section{참고문헌}

[1] Act on safety control of radioactive rays around living environment, Ministry of Goverment Legislation, 2012.

[2] Y. H. Jo, C. J. Kim, J. Y. Yoon, D. H. Jo, G. P. Kim, "External Exposure Due to Natural Radionuclides in Building Materials in Korean Dwellings", J. RADIATION PROTECTION, Vol. 37, No. 4, 2012.

[3] United Nations Scientific Committee on the Effects of Atomic Radiation. Sources and effects of ionizing radiation. Vol. I Sources. 2000

[4] United Nations Scientific Committee on Effects of Atomic Radiation. Sources and effects of ionizing radiation. UNSCEAR 2008 Report to the General Assembly with Scientific Annexes. Volume I. 2010.

[5] ICRP, 1990 Recommendation of the International Commission on Radiaological Protection, International Commission on Radiaological Protection, ICRP Publication 60, Oxford: Pergamon Press, 1990.

[6] European Commission, Exposure of air crew to cosmic radiation, Radiation Protection 85, EURADOS report 1996-04, 1996.

[7] M. Kelly, H. G. Menzel, T. Ryan and K. Schnuer, eds., "Cosmic Radiation and Aircrew Exposure, Proc. of an Int. Conf., Bublin, Ireland, July 1-3, 1998", Radiat. Proct. Dosim., Vol. 84, No. 4, 1999.

[8] J.M. Courades, "European Legislation on Protection Against Cosmic Radiation", Radiat. Prot. Dosim., Vol. 86, No. 4, pp. 343-345, 1999.

[9] Y.Y. Youn, S. Y. Cho, K. Y. Lee, and Y. J. Kim, "The Study of Radon and Uranium Distribution in the Groundwater at Regional Difference of Daejon", J. korea Asso, Radiat Prot, Vol. 31, No. 1, pp. 25-30, 2006.

[10] J.S Jeon and D. C. Kim, "Distribution of Rn222 Concentration in Seoul Subway Stations", J. korean Soc of Environmental Engineers, Vol. 28, No. 6, pp. 588-595, 2006.

[11] T.J. Ji, I. S. Lee, "Measurement of Environmental Radiation according to Altitude above Sea Level in National Park", Journal of Korea Contents Association, Vol. 12, No. 12, 2012.

[12] E.J. Hall, A. J Giaccia, Radiobiology for the radiologist, 6th ed, LWW. USA, pp. 187-219, 2006.
[13] J. H. Hong, J. W. Kwon, J. H. Jung and J. K. Lee, "Calculation of Route Doses for Korean-based International Airline Routes using CARI-6 and Estimation of Aircrew Exposure, Vol. 29, No. 2, pp. 141 150, 2004. 